\title{
Analysis of Nuclear Track Parameters of CN-85 Detector Irradiated to Thermal Neutrons by Using MATLAB Program
}

\author{
Hussain A. Al-Jobouri1 ${ }^{*}$, Mustafa Y. Rajab', Laith A. Najam² \\ ${ }^{1}$ Department of Physics, College of Science, AL-Nahrain University, Baghdad, Iraq \\ ${ }^{2}$ Department of Physics, College of Science, University of Mosul, Mosul, Iraq \\ Email: ${ }^{\text {hahmed54@gmail.com }}$
}

Received 15 July 2015; accepted 23 August 2015; published 26 August 2015

Copyright (C) 2015 by authors and Scientific Research Publishing Inc.

This work is licensed under the Creative Commons Attribution International License (CC BY). http://creativecommons.org/licenses/by/4.0/

\section{Abstract}

CN-85 detector which covered with boric acid $\mathrm{H}_{3} \mathrm{Bo}_{3}$ pellete has been irradiated by thermal neutrons from $\left({ }^{241} \mathrm{Am}-{ }^{-} \mathrm{Be}\right)$ source with activity $12 \mathrm{Ci}$ and neutron flux $10^{5} \mathrm{n} \cdot \mathrm{cm}^{-2} \cdot \mathrm{s}^{-1}$. The irradiation times-T for detector were $4 \mathrm{~h}, 8 \mathrm{~h}, 16 \mathrm{~h}$ and $24 \mathrm{~h}$. The track detector has been etched with sodium hydroxide. After chemical etching of the irradiated $\mathrm{CN}-85$ detector, the images have been taken from a digital camera connected to the optical microscope. Image processing for the output images has been performed using MATALB program, and these images were analyzed and we had found the following relations: a) The relation between summation of opened track or surface density for tracks (intensity- $\mathrm{I}_{\mathrm{T}}$ ) varies with radius of opening (track radius- $\mathrm{R}_{\mathrm{T}}$ ). b) The relation between the tracks number- $\mathrm{N}_{\mathrm{T}}$ varies with the tracks diameter- $\mathrm{D}_{\mathrm{T}}$ (in micrometer) and tracks area- $\mathrm{A}_{\mathrm{T}}$. That analysis of image processing was obtained, and the track intensity- $I_{T}$ was decreased with increase of track radius- $R_{T}$ at all of the irradiation time- $T_{D}$. And the track intensity- $I_{T}$ was increased with increasing irradiation time- $\mathrm{T}_{\mathrm{D}}(\mathrm{h})$ for different track radius- $\mathrm{R}_{\mathrm{T}}(0.4225,0.845,1.2675$ and $1.69 \mu \mathrm{m})$. The study indicates the possibility of using the analysis of image processing to $\mathrm{CN}-85$ detector for classification of $\alpha$-particle emitters through limitation of radius of track- $\mathrm{R}_{\mathrm{T}}$, in addition to the contribution of these techniques in preparation of nano-filters and nono-membrane in nanotechnology fields.

\section{Keywords}

Nuclear Track Detectors, Thermal Neutron, MATLAB Program, Image Processing

\footnotetext{
${ }^{*}$ Corresponding author.
}

How to cite this paper: Al-Jobouri, H.A., Rajab, M.Y. and Najam, L.A. (2015) Analysis of Nuclear Track Parameters of CN-85 Detector Irradiated to Thermal Neutrons by Using MATLAB Program. Detection, 3, 29-36. 


\section{Introduction}

Cellulose nitrate detector is one of organic nuclear track detectors [1] and common type of cellulose nitrate is $\mathrm{CN}-85$ detector. And this detector contains in chemical composition on nitrogen which has a chemical structure $\mathrm{C}_{6} \mathrm{H}_{18} \mathrm{O}_{5} \mathrm{~N}_{2}$. CN-85 detector is one of the good detectors for the detection of neutrons and charged particles such as protons, $\alpha$-particles, fission fragments and heavy ions [2]-[4]. There are a number of programs that are used in image processing for digital images. One of these programs is MATLAB, which used the image processing in many application fields [5]-[9]. Image analysis for nuclear track detectors-NTDs was one of these applications.

In 2006 Patiris, D. L. et al. [10] used a computer program named TRIAC written in MATLAB which has been developed for track recognition and track parameters measurements from images of the solid state nuclear track detectors type CR-39. The program using image analysis tools counts the number of tracks for dosimetry proposes and classifies the tracks according to their radii for the spectrometry of alpha-particles as using same computer program named TRIAC II has been developed for recognition and parameters measurements of particles "tracks" from images of solid state nuclear track detectors. In Fuminobu Sato et al. (2007) [11] observation system was developed to record time-lapse images of etch pits formed on the surface of a solid-state nuclear track detector-SSNTD type CR-39.

After that in 2008 Mostofizadeh, A. et al. [12], used MATLAB program as method to study edge detection, all measurements carried out in two cases of before and after improvement of track images. Considering the overlapping phenomenon - including double and triple tracks-experimental and statistical results showed that not only each particular edge detection method affects the accuracy of measurements. The tracks were randomly seeded on the film to simulate the irradiation by alpha particles emitted by the naturally occurring radon gas and its short-lived progeny. The ray-tracing method was applied to simulate light propagation through the tracks. The total amount of scattering increased linearly with the track density and quadratic ally with the removed layer during chemical etching of the irradiated CR-39 detector.

In 2013 Osinga, J.M. et al. [13] used $\mathrm{Al}_{2} \mathrm{O}_{3}: \mathrm{C}$, Mg-based fluorescent nuclear track detectors-FNTDs and confocal laser scanning microscopy as a semiautomatic tool for fluence measurements in clinical ion beams. Then Firas M. Al-Jomaily, et al. [14], used MATLAB program to determine the nuclear track parameters such as track diameter- $\mathrm{D}_{\mathrm{T}}(\mu \mathrm{m})$, number of track- $\mathrm{N}_{\mathrm{T}}$ and track area- $\mathrm{A}_{\mathrm{T}}$ for LR-115 detector which irradiated by alpha particle. In this study, the nuclear track parameters will be analyzed for $\mathrm{CN}-85$ detector which is calculated by MATLAB program with the irradiation time- $\mathrm{T}_{\mathrm{D}}$, and its relationship with track diameter- $\mathrm{D}_{\mathrm{T}}(\mu \mathrm{m})$.

\section{Material and Methods}

Solid state nuclear track detector SSNTDs-type CN-85 was manufactured by Kodak-Pathe, France. CN-85 detector was in the form of sheets with thickness $0.1 \mathrm{~mm}$. These sheets were cut into four pieces with dimensions 1 $\mathrm{cm} \times 1 \mathrm{~cm}$. And the species covered with boric acid- $\mathrm{H}_{3} \mathrm{Bo}_{3}$ pellets which propagate by pressed $0.5 \mathrm{~g}$ of $\mathrm{H}_{3} \mathrm{Bo}_{3}$ in piston for $30 \mathrm{~s}$ under pressure 150 par. The dimensions of steel piston mould were $1 \mathrm{~mm}$ thickness and $2 \mathrm{~cm}$ diameter. $\mathrm{CN}-85$ detectors covered with pellets of boric acid- $\mathrm{H}_{3} \mathrm{Bo}_{3}$ to convert free thermal neutrons to $\alpha$-particle through ${ }^{10} \mathrm{~B}(\mathrm{n}, \alpha)^{7} \mathrm{Li}$ interaction [15] (Figure 1(b). The samples of CN-85 detectors and boric acid pellets were putted around the paraffin wax as shown in (Figure 1(a)).

The source of thermal neutron was ${ }^{241} \mathrm{Am}-{ }^{9} \mathrm{Be}$ with activity $12 \mathrm{Ci}$, neutron flux $10^{5} \mathrm{n} . \mathrm{cm}^{-2} . \mathrm{s}^{-1}$, with $5 \mathrm{~cm}$ distance between the source and samples. The irradiation times- $T_{D}$ of thermal neutrons were $4 \mathrm{~h}, 8 \mathrm{~h}, 16 \mathrm{~h}$ and $24 \mathrm{~h}$. After samples irradiated, the boric acid pellets has been removed taken from $\mathrm{CN}-85$ detectors. Chemical etching process for $\mathrm{CN}-85$ has been done by using sodium hydroxide $\mathrm{NaOH}$ solution with $2.5 \mathrm{~N}$ at etching time; 15 min and temperature; $50^{\circ} \mathrm{C}$. The counting of chemically etched tracks was carried out using optical microscope (type Motic, Malaysia). It is capable of giving magnifications of $400 \times$ and eyepiece $10 \times$ to measure the number of tracks. The type of eye piece was scalar to calculate the number of tracks. The optical microscope was connected with digital camera which has 1.3 Mega pixel and high resolution USB 2.0 with color digital image system. Image processing for output images have been performed using MATLAB program version R2013b (8.2.0.701) for 64 bit (win 64). Take images for detectors which contain on the nuclear tracks and store these images (pixel unit) in computer at the form (jpg. file). One pixel in these image was equal to converting factor $0.4225 \mu \mathrm{m}$ which calculated experimentally by using of role scale in optical microscope and take into account in the input program of MATLAB image processing. 


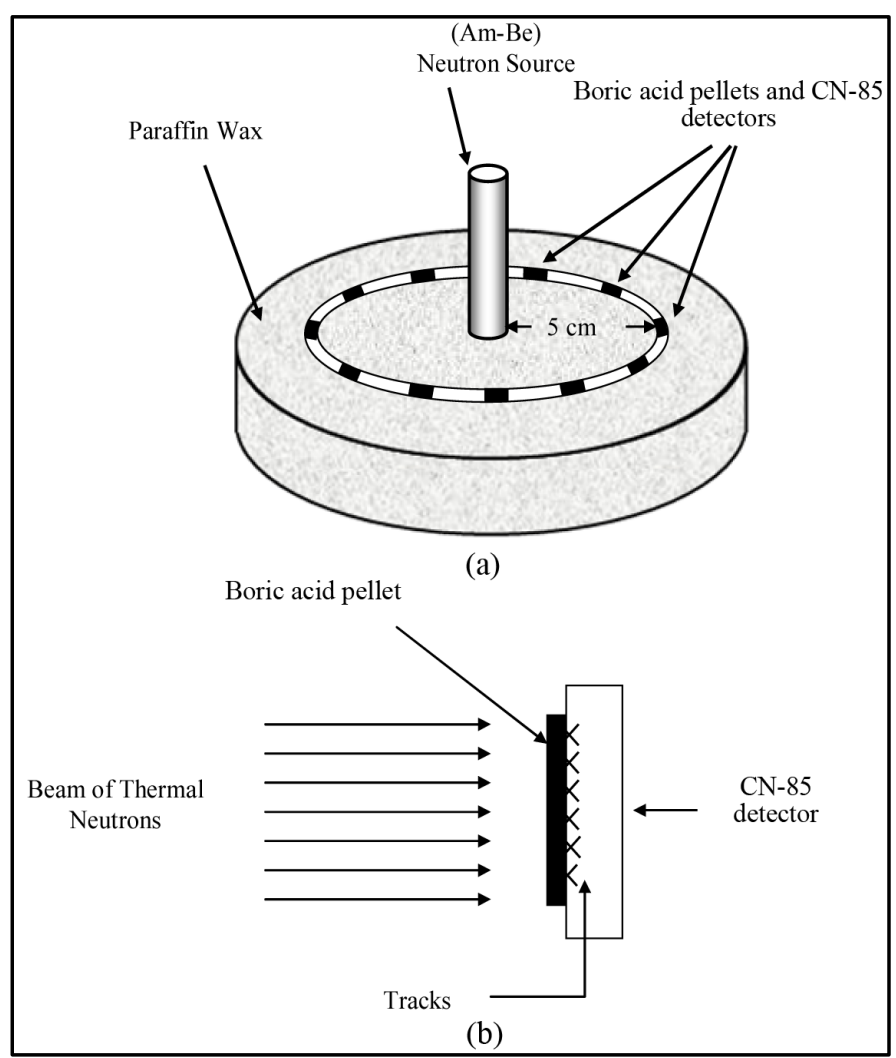

Figure 1. Diagram of CN-85 detector irradiation by thermal neutrons. (a) Locations of $\left({ }^{241} \mathrm{Am}-{ }^{9} \mathrm{Be}\right)$ source, $\mathrm{CN}-85$ detector covered with boric acid pellets and paraffin wax; (b) Principle of convert free thermal neutrons to $\alpha$-particle through ${ }^{10} \mathrm{~B}$ (n, $\alpha)^{7} \mathrm{Li}$ interaction [15].

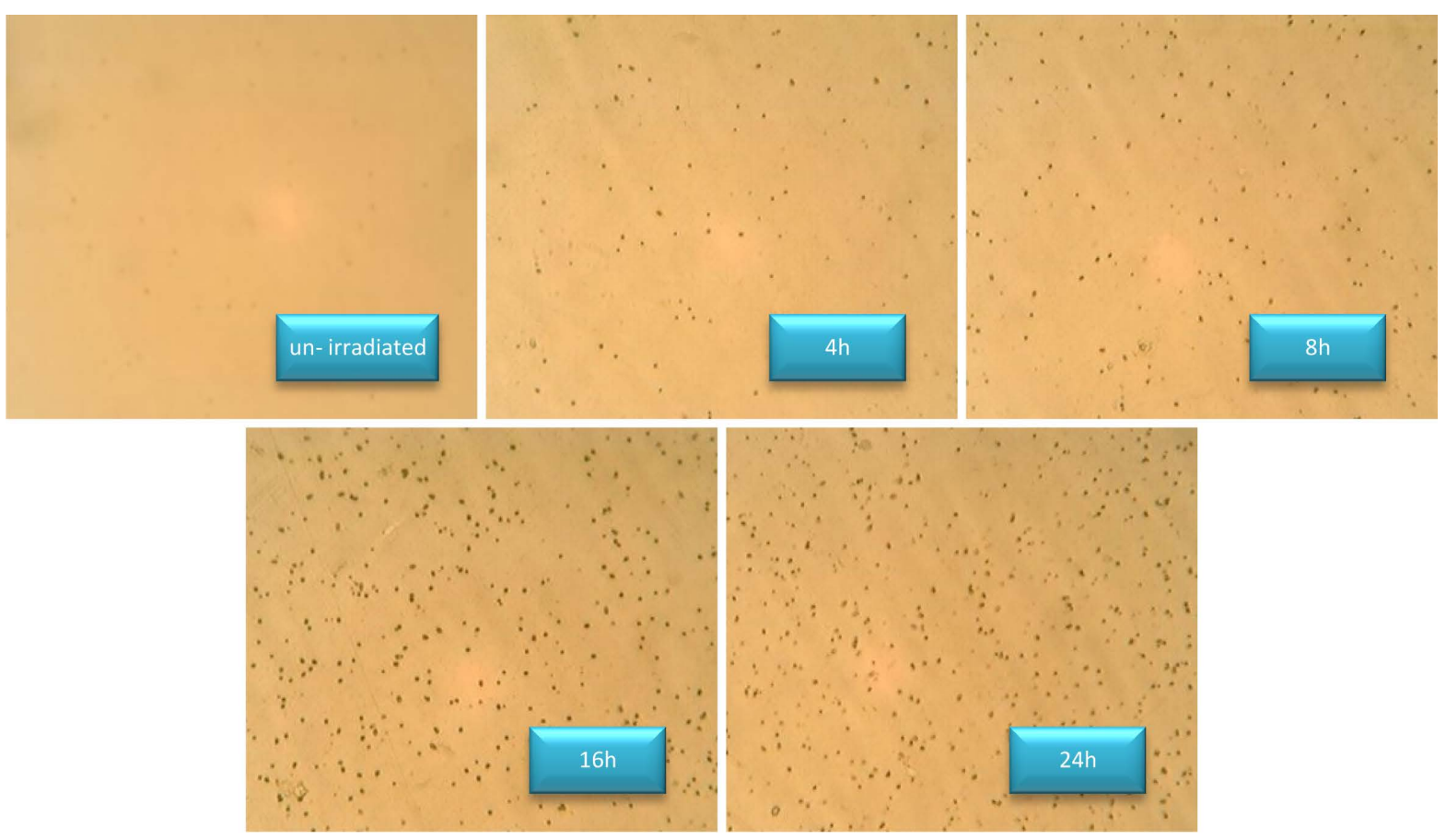

Figure 2. Images by optical microscope of CN-85 detector irradiated with thermalneutrons for different times (un-irradiated, 4 h, 8 h, 16 h and 24 h). 


\section{Results and Discussion}

Figure 2 shows the nuclear track detector CN-85 irradiation by thermal neutron at different time 4 h, 8 h, 16 h, and $24 \mathrm{~h}$. From this figure show increasing in the tracks with increasing of irradiation time compare with nonirradiated detector.

Figure 3(a) shows the first step from image processing of MATLAB program for the image of tracks in $\mathrm{CN}-85$ detector after irradiation time $24 \mathrm{~h}$ by thermal neutron before image analysis.

While, Figure 3(b) shows same image after treatment the background of unwanted impurities and distortions on the detector.

Figure 4 shows the second step in image processing and shows the real image for tracks which convert from (Figure 3(b)) to binary system.

Figure 5 shows the third step in image processing by determination the relationship between the pixel value summation of opened track or surface density for tracks (intensity- $\mathrm{I}_{\mathrm{T}}$ ) with radius of opening of track- $\mathrm{R}_{\mathrm{T}}$ (in pixal). And obtained the radius of opening of track was increase when the surface density for track decreases.

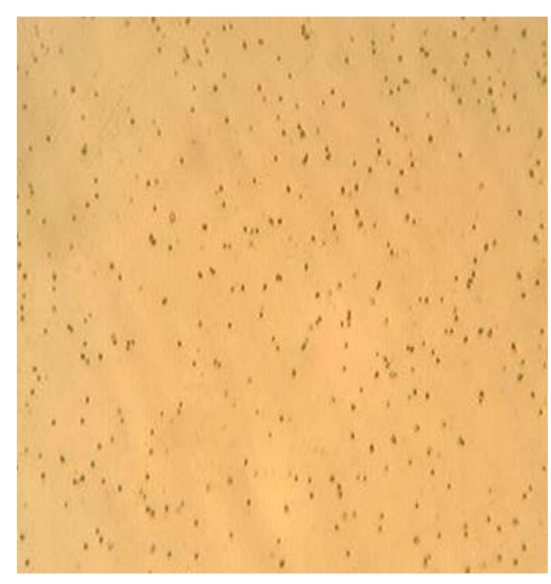

(a)

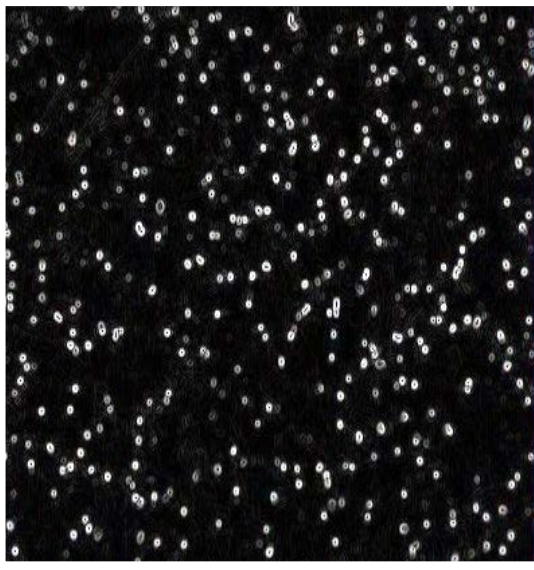

(b)

Figure 3. First step from image processing of MATLAB program which obtained the track image in $\mathrm{CN}-85$ detector after $24 \mathrm{~h}$ irradiated time by thermal neutrons. (a) Before image processing; (b) After image processing.

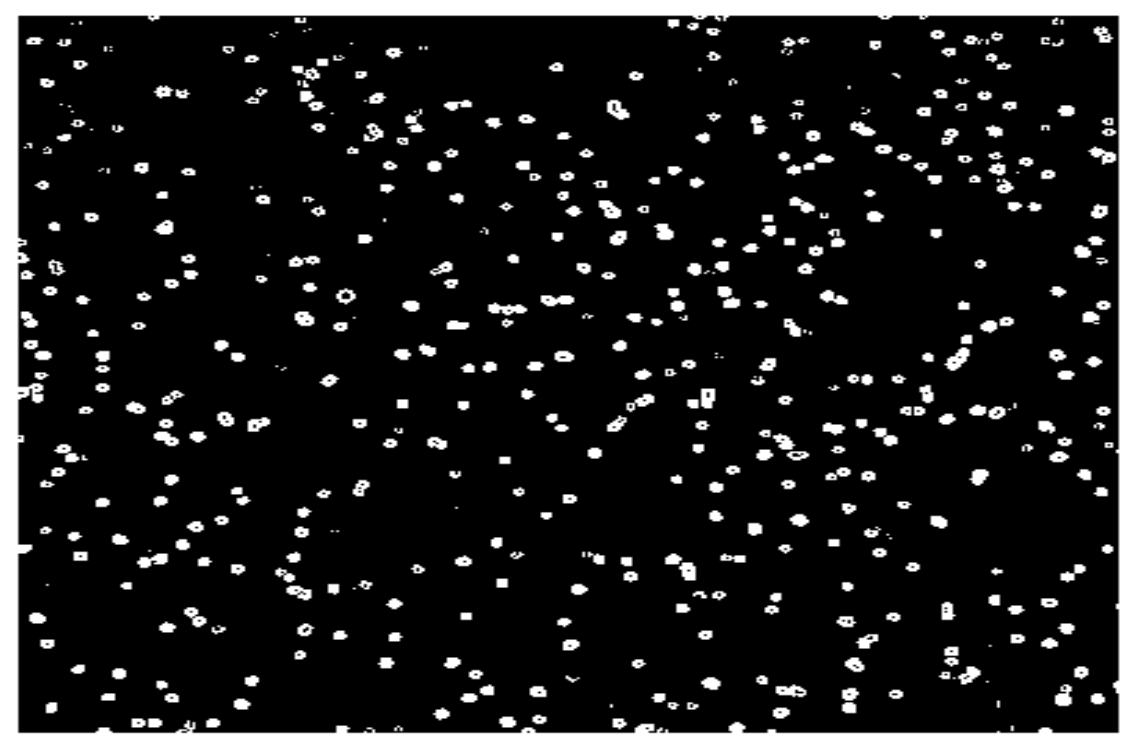

Figure 4. Second step from image processing of MATLAB program which obtained from converting to binary system in $\mathrm{CN}-85$ detector after $24 \mathrm{~h}$ irradiated time. 
The forth step in Figure 6 appears pseudo coloring map for tracks of CN-85 detector. The color type of track dependent on the diameter or track area- $\mathrm{A}_{\mathrm{T}}$.

Figure 7 displays the relationship between the number of tracks- $\mathrm{N}_{\mathrm{T}}$ and diameter of track- $\mathrm{D}_{\mathrm{T}}$ which represent as the fifth step from image processing. From this figure obtained the maximum diameter- $\mathrm{D}_{\mathrm{T}}$ appear in following track diameter- $\mathrm{D}_{\mathrm{T}}(3.66,1.93,2.53$ and $4.8 \mu \mathrm{m})$.

The final step for relationship between the tracks number- $\mathrm{N}_{\mathrm{T}}$ and of track area- $\mathrm{A}_{\mathrm{T}}$ was obtained in Figure 8. From this figure show the maximum of track number- $\mathrm{N}_{\mathrm{T}}$ appear at the track area- $\mathrm{A}_{\mathrm{T}}$ with value $21.4 \mu \mathrm{m}^{2}$.

Figure 9 shows comparison for the relations between track intensity- $\mathrm{I}_{\mathrm{T}}$ for $\mathrm{CN}-85$ with track radius- $\mathrm{R}_{\mathrm{T}}$ for different irradiation time- $\mathrm{T}_{\mathrm{D}}$, which show there was decrease in track intensity- $\mathrm{I}_{T}$ with increase of track radius- $\mathrm{R}_{\mathrm{T}}$.

From Figure 9, the track intensity- $\mathrm{I}_{\mathrm{T}}$ was decrease with increase of track radius- $\mathrm{R}_{\mathrm{T}}$ at all of the irradiation time- $\mathrm{T}_{\mathrm{D}}$ until to track radius- $\mathrm{R}_{\mathrm{T}} ; 2.11 \mu \mathrm{m}$ at all irradiation time- $\mathrm{T}_{\mathrm{D}}$. Where Figure 10 , shows linearly relationship between track intensity- $\mathrm{I}_{\mathrm{T}}$ and irradiation time- $\mathrm{T}_{\mathrm{D}}$ at different track radius- $\mathrm{R}_{\mathrm{T}}(0.4225,0.845,1.2675$ and $1.69 \mu \mathrm{m}$ ) which calculate from Figure 9.

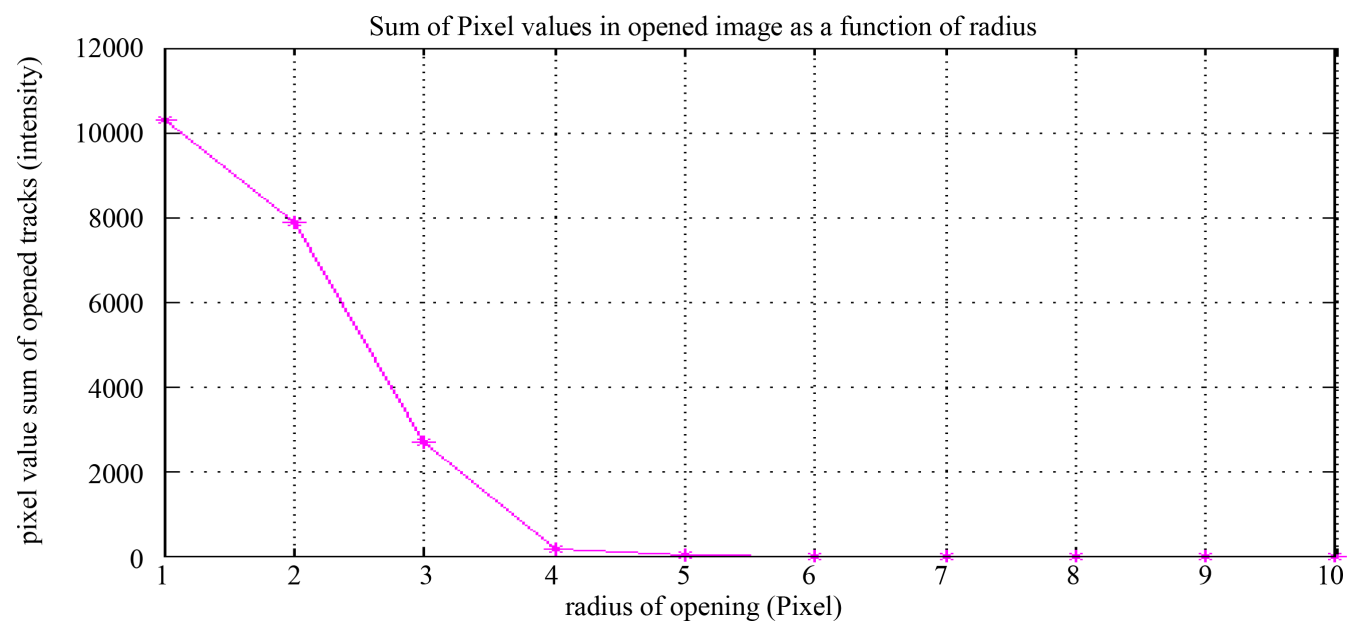

Figure 5. Third step from image processing of MATLAB program which obtained value summation of opened track or surface density for tracks (intensity- $\mathrm{I}_{\mathrm{T}}$, in pixel) varies with radius of opening (track radius- $\mathrm{R}_{\mathrm{T}}$, in pixel) for irradiated CN-85 detector at time $24 \mathrm{~h}$.

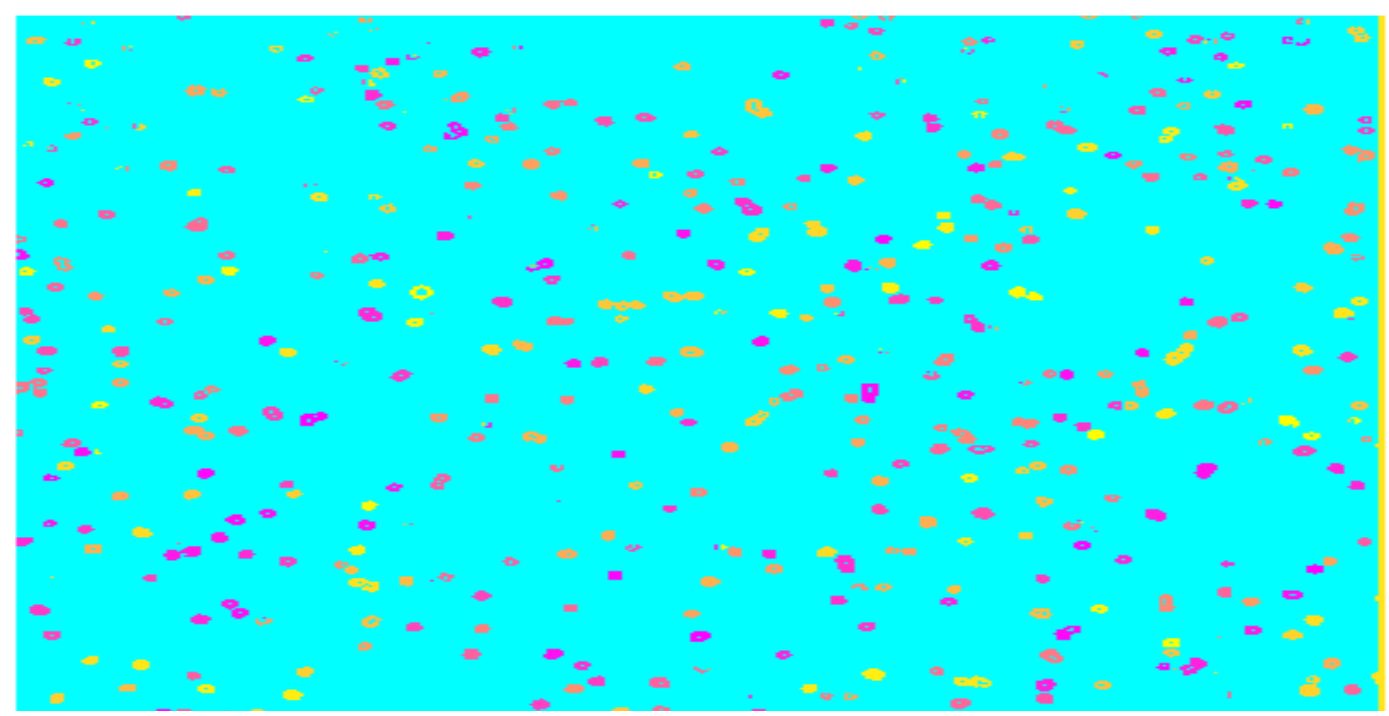

Figure 6. Forth step from image processing of MATLAB program which appear pseudo coloring map for tracks of $\mathrm{CN}-85$ detector. 


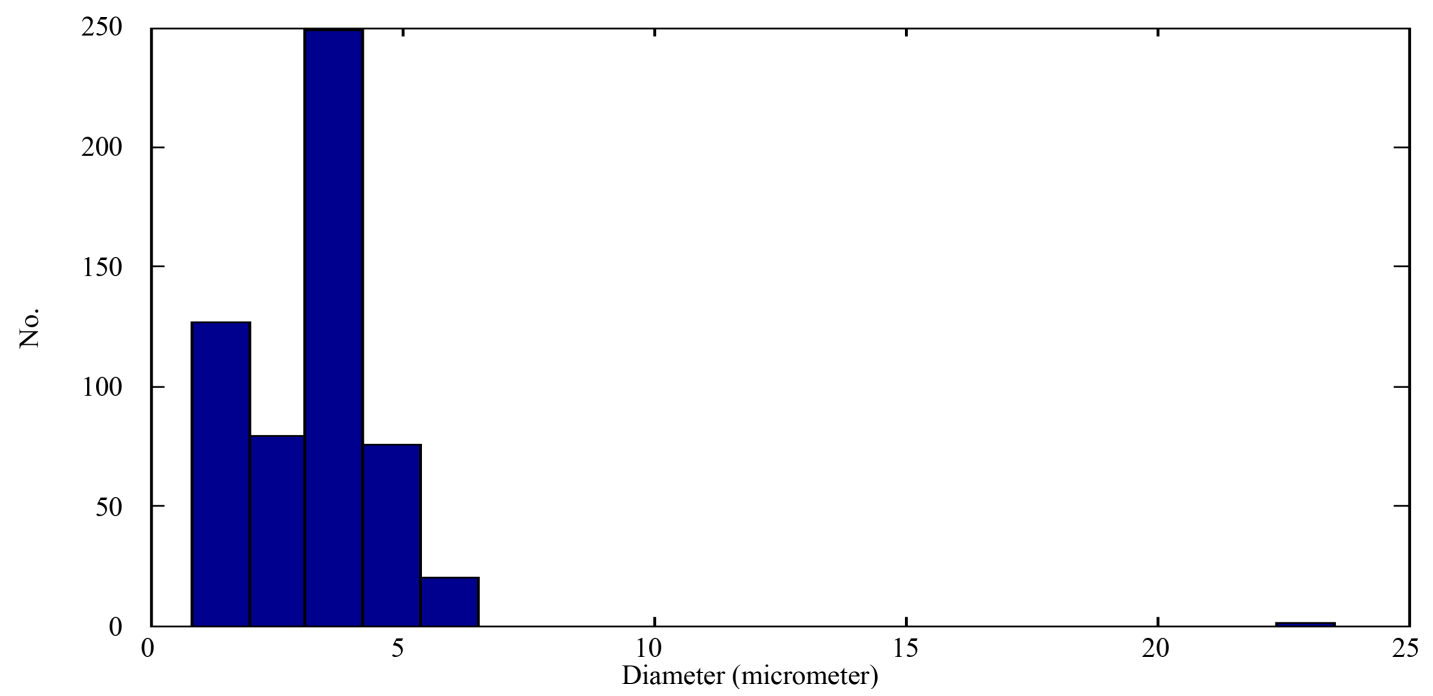

Figure 7. Fifth step from image processing of MATLAB program which obtained the histogram between the tracks number- $\mathrm{N}_{\mathrm{T}}$ (NO.) and the tracks diameter- $\mathrm{D}_{\mathrm{T}}$ (Diameter; micrometer) for irradiated CN-85 detector at $24 \mathrm{~h}$.

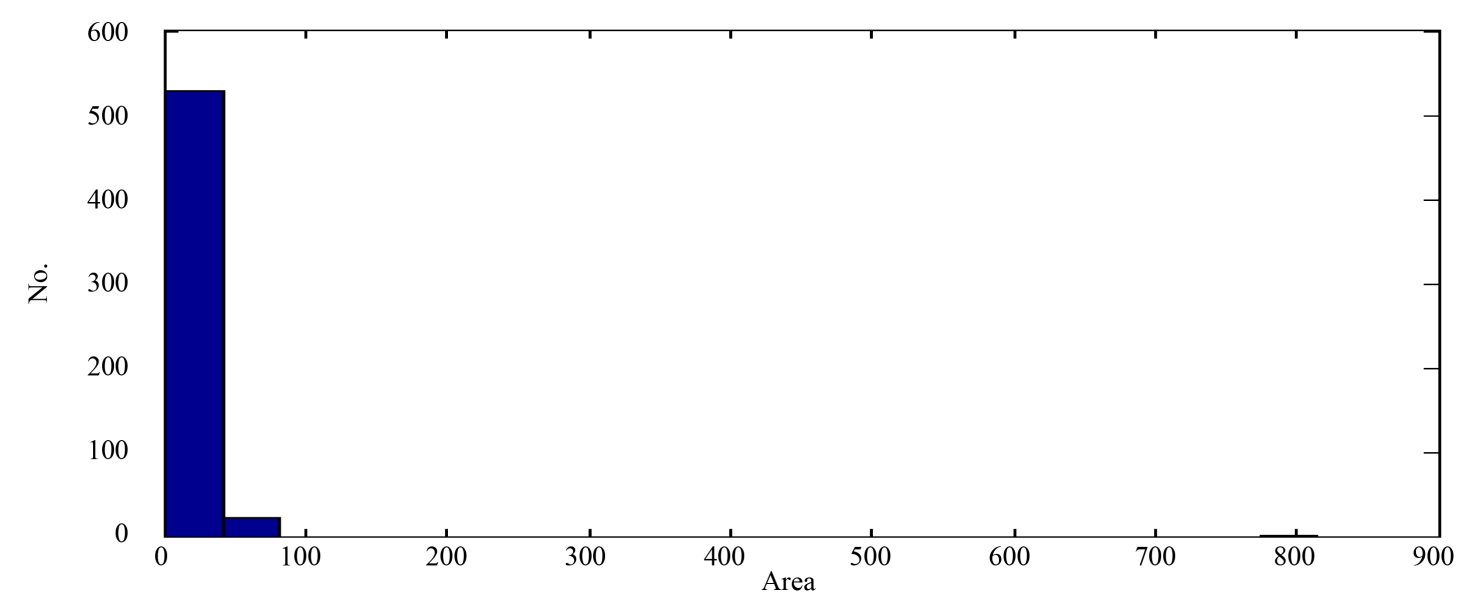

Figure 8. Six step from image processing of MATLAB program which obtained the histogram between the tracks number- $\mathrm{N}_{\mathrm{T}}$ (NO.) and the tracks area- $\mathrm{A}_{\mathrm{T}}$ (Area) for irradiated $\mathrm{CN}-85$ detector at $24 \mathrm{~h}$.

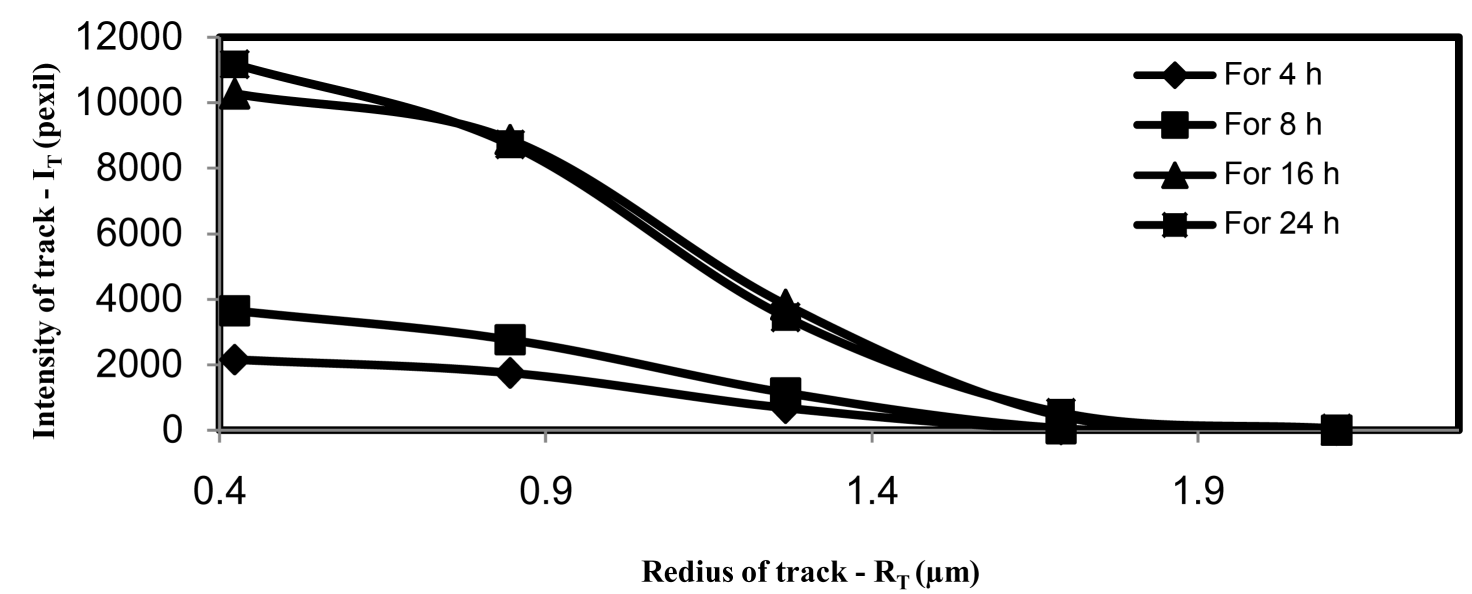

Figure 9. Relation between track intensity- $\mathrm{I}_{\mathrm{T}}$ (pixel) for $\mathrm{CN}-85$ with track radius- $\mathrm{R}_{\mathrm{T}}$ at different irradiation time- $\mathrm{T}_{\mathrm{D}}$ for $4 \mathrm{~h}, 8 \mathrm{~h}, 16 \mathrm{~h}$ and $24 \mathrm{~h}$. 


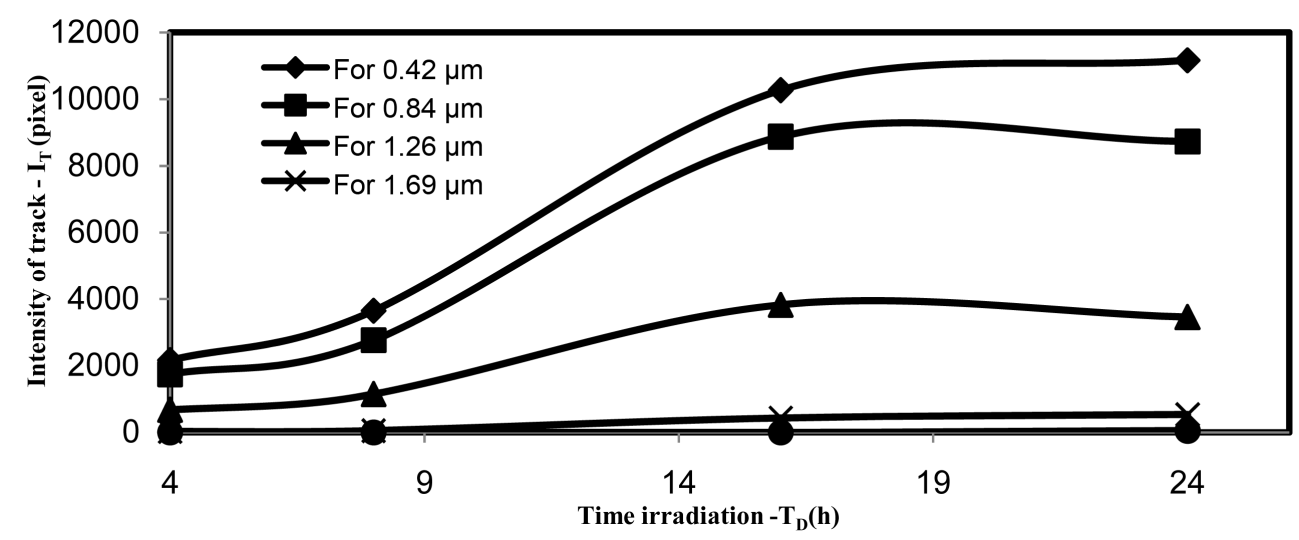

Figure 10. Relation between track intensity- $\mathrm{I}_{\mathrm{T}}$ for $\mathrm{CN}-85$ with irradiation time- $\mathrm{T}_{\mathrm{D}}$ (h) for different radius of track- $\mathrm{R}_{\mathrm{T}}(0.4225,0.845,1.2675,1.69$ and $2.11 \mu \mathrm{m})$.

From Figure 10, shows the track intensity- $\mathrm{I}_{T}$ was increase with increase of irradiation time- $\mathrm{T}_{\mathrm{D}}$ for all track radius- $\mathrm{R}_{\mathrm{T}}$, and the maximum response was at track radius- $\mathrm{R}_{\mathrm{T}}$ value $0.4225 \mu \mathrm{m}$.

\section{Conclusion}

The analysis, which is obtained by image processing technique of MATLAB program for CN-85 detector, can be determined for other nuclear track detectors, and also for other particle radiations. The behavior which calculated from this study for track radius- $\mathrm{R}_{\mathrm{T}}$ with irradiation time- $\mathrm{T}_{\mathrm{D}}$ can be used to obtain the amount of energy for $\alpha$-particle and determine the type of $\alpha$-particle emitters. The image analyses, which are determined by MATLAB program for the $\mathrm{CN}-85$ detector, specialized nuclear track radius- $\mathrm{R}_{\mathrm{T}}$, can be used in the nanotechnology studies. Where the preparation of nano filters and nano membrane from NTDs depends on the nuclear track radius- $\mathrm{R}_{\mathrm{T}}$ [16] as the indicator to reach of the requirements specifications.

\section{References}

[1] Sidorov, M. and Ivanov, O. (2010) Nuclear Track Detectors: Design, Methods and Applications. Electrical Engineering Developments.

[2] Barbui, M., Fabris, D., Moretto, S., Nebbia, G., Nemeth, P., Palfalvi, J., Pesente, S., Prete, G., Sajo-Bohus, L. and Viesti, G. (2009) Nuclear Tracks in PADC Induced by Neutron, Heavy Ion and Energetic Fragments Formed in the Reaction ${ }^{54} \mathrm{Cr}+{ }^{208} \mathrm{~Pb}$ at $320 \mathrm{MeV}$. Radiation Measurements, 44, 857-860.

[3] Ali, N., Khan, E.U., Ahmad, N., Abbas, S.M. and Iqbal, M.A. (2014) Photo-Spectro-Metric Study of CR-39 Detectors Irradiated with Heavy Ions. Pakistan Journal of Engineering and Applied Sciences, 15, 68-75.

[4] Saad, A.F., Hamed, N.A. and Abdalla, Y.K. (2013) Identification of Spontaneous Fission Fragments by Using Thermally Annealed PADC Films. Turkish Journal of Physics, 37, 356-362.

[5] Maheshwari, V., Jain, K.R. and Modi, C.K. (2012) Non-Destructive Quality Analysis of Indian Gujarat-17 Oryza Sativa Sspindica (Rice) Using Image Processing Chetna. International Journal of Computer Engineering Science (IJCES), 2, 48-54.

[6] Nagle, M., Kiatkamjon, I., Busarakorn, M., Vicha, S. and Joachim, M. (2012) Non-Destructive Mango Quality Assessment Using Image Processing: Inexpensive Innovation for the Fruit Handling Industry. Conference on International Research on Food Security, Natural Resource Management and Rural Development, Göttingen, 19-21 September 2012, 1-4.

[7] Abdellah, H., El. Kouraychi, A., Abdenabi, B. and Ahmed, R. (2012) Defects Detection and Extraction in Textile Imageries Using Mathematical Morphology and Geometrical Features. Journal of Signal Processing Theory and Applications, 1, 1-16.

[8] Raju, R., Ch.Ravi, M. and Kumar, S. (2012) Image Processing of Liquid Crystal Mesogen Exhibiting Nematic Phase. Signal \& Image Processing: An International Journal (SIPIJ), 3, 13-21. http://dx.doi.org/10.5121/sipij.2012.3402

[9] Sefidgari, B.L. (2013) Feed-Back Method Based on Image Processing for Detecting Human Body via Flying Robot. International Journal of Artificial Intelligence and Applications (IJAIA), 4, 35-44. http://dx.doi.org/10.5121/ijaia.2013.4604 
[10] Patiris, D.L. and Ioannides, K.G. (2009) Discriminative Detection of Deposited Radon Daughters on CR-39 Track Detectors Using TRIAC II Code. Nuclear Instruments and Methods in Physics Research Section B: Beam Interactions with Materials and Atoms, 267, 2440-2448. http://dx.doi.org/10.1016/j.nimb.2009.04.009

[11] Sato, F., Kuchimaru, T., Kato, Y. and Iida, T. (2008) Digital Image Analysis of Etch Pit Formation in CR-39 Track Detector. Japanese Journal of Applied Physics, 47, 269-272. http://dx.doi.org/10.1143/JJAP.47.269

[12] Mostofizadeh, A., Sun, X. and Kardan, M.R. (2008) Improvement of Nuclear Track Density Measurements Using Image Processing Techniques. American Journal of Applied Sciences, 5, 71-76 http://dx.doi.org/10.3844/ajassp.2008.71.76

[13] Osinga, J.M., Akselrod, M.S., Herrmann, R., Hable, V., Dollinger, G., Jäkel, O. and Greilich, S. (2013) High-Accuracy Fluence Determination in Ion Beams Using Fluorescent Nuclear Track Detectors. Radiation Measurements, 56, 294298. http://dx.doi.org/10.1016/j.radmeas.2013.01.035

[14] Al-Jomaily, F.M., Al-Jobouri, H.A. and Mheemeed, A.K. (2013) Determination of Nuclear Track Parameters for LR115 Detector by Using of MATLAB Software Technique. Journal of Al-Nahrain University, 16, 117-124.

[15] Smilgysa, B., Guedesa, S., Moralesb, M., Alvarezb, F., Hadlera, J.C., Coelhoc, P.R.P., Siqueirac, P.T.D., Alencara, I., Soaresa, C.J. and Curvo, E.A.C. (2013) Boron Thin Films and CR-39 Detectors in BNCT: A Method to Measure the ${ }^{10} \mathrm{~B}(\mathrm{n}, \alpha)^{7} \mathrm{Li}$ Reaction Rate. Radiation Measurements, 50, 181-186. http://dx.doi.org/10.1016/j.radmeas.2012.07.001

[16] Ziaie, F., Shadman, M., Yeganegi, S., Mollaie, A. and Majdabadi, A. (2009) Investigation on Polycarbonate Nanomembrane Production Based on Alpha Particles Irradiation. NUKLEONIKA, 54, 157-161. 